\title{
Strategizing of Regional Sustainable Development: Conceptual Provisions and Modern Tools
}

\author{
Svetlana Mudrova ${ }^{1, *}$, Elena Burdenko ${ }^{1}$, and Gagik Galstyan ${ }^{2}$ \\ ${ }^{1}$ Plekhanov Russian University of Economics, Department of Political Economy and History of \\ Economic Science, 117997 Moscow, 36 Stremyanny lane, Russia \\ ${ }^{2}$ Yerevan State University, Faculty of Economy and Management, 1 Alek Manukyan St., Yerevan \\ 0025, Armenia
}

\begin{abstract}
The article substantiates provisions aimed at improving the tools for implementing the strategy of sustainable spatial development of the Russian Federation, taking into account the processes of systemic digital transformation of the economy. The aim of the study is to substantiate a new methodological approach to the interpretation of the patterns of sustainable regional development, which considers the spatial and environmental factors as endogenous sources of sustainable growth. To achieve this goal, the stages of development of ideas about the regional economy and regional development were determined, the content of the spatial approach to the interpretation of economic phenomena and processes was clarified, recommendations were formulated aimed at improving the toolkit of regional policy, taking into account the structuredness and multipolarity of the Russian economic, environmental and information space. The result of the study is the conclusion about the heterogeneity of the space of Russian regions and the need to take into account environmental space quality indicators when developing program measures for sustainable development, as well as in assessing their effectiveness.
\end{abstract}

\section{Introduction}

Spatial polarization in the form of interregional inequality is a significant risk factor for delaying the transition to sustainable development in the long term, entering a positive trend of stable dynamics at the macrolevel of the economy. A slight decrease in imbalances between the constituent entities of the Russian Federation, which was the result of the implementation of a set of measures of government regulations in the period from 2010 to 2016, gave way to a trend of further deepening of interregional imbalances. In the context of the global economic crisis and sanctions restrictions from a number of foreign states in relation to Russia, it becomes necessary to search for endogenous factors of sustainable development and stable macroeconomic dynamics, which include the spatial variability of assets and the digitalization of the economic space. The need to clarify the composition of

\footnotetext{
${ }^{*}$ Corresponding author: Mudrova.SV@,rea.ru
} 
tools for spatial strategizing of sustainable development of the Russian economy determines the promising relevance of research in this area.

\section{Materials and Methods}

Analysis of the instruments of state regulation of sustainable development of Russian regions made it possible to conclude that at the first stages they were formed in accordance with the provisions of the theory of regional economics, while the modern stage (2015 present) is characterized by an attempt to implement the principles of the spatial paradigm, which is confirmed by the provisions of the Strategy Spatial Development of the Russian Federation for the Period up to 2025. At the same time, it should be recognized that this document is characterized by eclecticism and some declarativeness, which is reflected in the interpretation of a number of key categories, in a simplified view of the conditions of spatial equilibrium and patterns of spatial development, in the underestimation of introduction of end-to-end digital technologies and platform solutions in all spheres of life for interregional and intraregional proportions. In this regard, it seems necessary to adjust the goal, objectives of the Strategy and the content of the stages of strategic planning.

To understand the qualitative differences between the principles of the spatial approach and the provisions of the theories of regional economy sustainable development, it is necessary to turn to the process of formation of modern concepts of territorial organization [1-2]. The formation of a methodological platform for sustainable spatial development and spatial strategizing required a retro-analysis of ideas about the region as a taxonomic unit, and economic environment as an evolving phenomenon [3-4]. Analysis of alternative approaches to the patterns of sustainable regional development made it possible to distinguish its three stages:

1. The pre-market stage, which gave rise to separate ideas about the economy of the region as a territorial entity, which is identified in accordance with geographic and political characteristics (before the beginning of the 18th century). In particular, pre-scientific ideas about the peculiarities of regional economy development were formulated within the framework of mercantilism.

2. The stage of the classical market and the beginning of the formation of a regulated market economy (XVIII - first half of the XX centuries), within which the theory of regional economics is being formed. At the same time, the region was determined taking into account the totality of economic factors (not environmental ones). The first scientific ideas about the regional economy were formed within the framework of the classical school of political economy - the idea of the dependence of the level of factor productivity on the territory of their location laid the foundation for the development of theories of international and interregional trade. Representatives of location and standard theories, macroeconomic approaches to regional development, theories of "growth poles" and "development axes", etc., made a significant contribution to the development of the theory of regional economics.

3. The stage of the regulated market (the second half of the XX - the beginning of the XXI centuries), characterized by the processes of networkization, informatization, globalization, which gave rise to the spatial paradigm and the theory of spatial economics and environment. Within the framework of the current stage in the development of ideas about the economic environment, there are theories of diffusion of innovations, the theory of sustainable regional growth, and the theory of the network economy. 


\section{Results and Discussion}

Conceptual approaches to the formation of regional policy and tools for systemic digital transformation are presented in a number of policy documents of the Russian state, including: the Strategy for the Spatial Development of the Russian Federation for the Period up to 2025, the Strategy for the Development of the Information Society in the Russian Federation for 2017-2030, the national program "Digital Economy of the Russian Federation with a Period of Implementation until 2024", programs for long-term socioeconomic development of Russian regions, etc.

In contrast to the theories of regional economy, based on the principles of the classical school, and theories of regional economics, which proceed from the provisions of the orthodox schools (neoclassical synthesis), the spatial theory, which, in accordance with the principles of heterodox economic science, uses a holistic approach to the analysis of spatial formations and recognizes them noncompositionality, fractality, heterogeneity, the ability to self-organize, to self-regulating and purposeful development, stability, adaptability, localization within permeable boundaries, openness, dissipation, emergence, integrity. The use of an interdisciplinary approach and the epistemological potential of philosophy, economic geography, economic sociology, environmental management and other areas of knowledge allows, within the framework of spatial economics, studying the evolution of institutions in relation to the transformation of economic and environmental factors.

Analysis of the properties of the economic and information space shows that they change significantly under the influence of the processes of globalization, networkization and digitalization.

Despite the variety of interpretations of the essence of globalization processes and their parameters, researchers admit that they “... assume fundamental changes in the spatial and time parameters of social life, in which the significance of space or territory changes due to a huge acceleration in the structure of the most important forms of human activity" [5] We agree with the definition of globalization as "the process of transforming a heterogeneous world space into a single global system in which information flows freely move, ... modifying the worldview, activities ... of institutions, communities and individuals and the mechanisms of their interaction" [5], as a process of decentralization of communications due to the emergence of a global network [6] with a simultaneous increase in the level of interconnection of local information flows. Localization in the meaning of an alternative to the process of globalization is interpreted as the adaptation of the global information process to the peculiarities of national (subnational) economic systems.

The objective prerequisites for globalization are: the formation of the Internet, the multiplicity of information sources, in which the recipients of information are simultaneously its switches, the convergence and unification of telecommunications, the development of "cloud" data processing technologies, the creation of information platforms, the formation of the "Internet of Things", that is Internet connection of physical devices, etc. Information platforms as a network form of space organization ensured an increase in the number of consumers of information products and their producers, regardless of the sphere of economic activity, and also contributed to overcoming territorial restrictions based on the inclusion of economic agents in a single reproduction process. Thus, globalization processes lead to the unification of spatial characteristics, to an increase in the level of permeability of subspaces and to an increase in its cohesion (unity).

The processes of networkization of the economic space lead to the formation of subregional formations - clusters, territories of advanced socio-economic development, special economic zones, etc. The level of asset specificity, the uncertainty of the external environment of the functioning of economic agents and the complexity of evaluating the results determine the dynamics of transaction costs, the increase of which stimulates the 
choice in favor of hierarchical form of management and leads to an increase in the number and size of firms that internalize transactions in relation to environmental saving and restoring assets. Such internalization occurs on the basis of the replacement of transactions (classical contracts) with coordination within the firm (relational contract), which explains their occurrence. A decrease in the level of specificity of the latter and the irregularity of contacts can lead to the replacement of the hierarchical form with a market form of environmental management [7].

In a homogeneous space, the market and hierarchy were the dominant forms of transaction management. The heterogeneity of the modern economic space has predetermined the need to use various hybrid transaction management tools based on incomplete contracts of the neoclassical type. This is due to the fact that as the size of the firm grows and management processes become more complex, the volume of internal transaction costs, or management costs described by a U-shaped curve, can exceed external (market) costs. Thus, the network forms of organizing economic activity are a hybrid form of managing regular transactions in relation to specific assets using incomplete neoclassical contracts in conditions of high uncertainty of environmental factors. Their formation contributes to the further process of structuring the economic space.

Systemic digital transformation of Russian regions includes: "digitalization and integration of vertical and horizontal value chains", "digitalization of products and services", "development of digital business models and provision of customer access", formation of "developed technological platforms" [8], development of competitive data transmission systems and provision of universal communication services based on innovations in all constituent entities of the Russian Federation. Digitalization is viewed as a process of forming the material basis for the transition from information society to communication society. Such a transformation presupposes the need for the federal Center to use quasi-centralized arbitration tools to synchronize communications of the systemic transformation of the information and communication space [9-10].

The heterogeneity of the information space is confirmed by the results of numerous studies. The list of methods used and planned includes: methods for assessing the digitalization of states; methods for assessing the level of digitalization of regions; methodology for assessing technologies and solutions, the level of digital literacy. As an indicator of the degree of integration, the share of interregional trade turnover in Russian GDP can be used. The indicator of involvement in the global economic space is the level of the region's dependence on foreign economic relations. The dynamics of interregional trade turnover correlates with the cyclical dynamics of macroeconomic indicators: a drop in its volume indicates an increase in divergence processes in the economic space and vice versa. As a part of the indicators of space heterogeneity, there are indices used by international organizations (World Bank, etc.), government bodies (Ministry of Digital Development, Communications and Mass Media of the Russian Federation, etc.), non-profit organizations (Fund for the Development of the Digital Economy, Institute for the Development of Information Society and etc.), as well as the indicator of the minimum digital basket of Russian regions [11], etc.

The information economy within the framework of this study is considered as a stage of development of the post-industrial technical and economic structure and as a synonym for the knowledge economy. The calculation of the index of the knowledge economy and the index of the level of knowledge is carried out both for individual countries and for a group of countries belonging to the Organization for Economic Cooperation and Development, as well as for developing countries. The process of comparing private sub-indices and the index of the knowledge economy of a certain state with the corresponding indicators of other countries contributes to obtaining information about the dynamics and characteristics of the development of the state for the period under study. For example, the downward 
dynamics of the country's knowledge economy index compared to the index of other states may be due to both a decrease in absolute indicators and their insufficient positive dynamics in comparison with the dynamics of the corresponding indicators of the compared states, which leads to a decrease in the number of points for the studied country in conditions of ordinal ranking.

In order to objectify data on the features of the processes of informatization of the economic space of the Russian Federation, it is necessary to conduct studies of regional formations, to identify the potential or limitations of systemic digital transformation. The expected result is the development of a system of indicators for a comprehensive analysis of the situation and the direction of development of the knowledge economy of the Russian Federation, proclaimed by experts from the IPRAN Institute of Russian Academy of Sciences. Using the selected indicators, it is proposed to study the knowledge economy from the standpoint of input and output industries based on the calculation of the following indicators [12]:

1. The share of investments in the knowledge economy of the Russian Federation in the value of GDP to the average value of this indicator for the countries of the European Union (EU) or the countries of the Organization for Economic Cooperation and Development (OECD).

2. The share of the use of information and intellectual resources in the socio-economic development and environmental management of the Russian Federation based on data on the expenditures of industries with high demand for education in GDP or the share of value added in GDP to the average value of this indicator in the EU or OECD countries.

3. The level of balanced development of the knowledge economy in the Russian Federation.

In particular, when calculating the knowledge economy index, specific sub-indices "Economic incentives and institutional environment", "Innovation potential and technological development", "Education and training system" and "Information and communication infrastructure" are used, which makes it possible to obtain an integral indicator of the level of post-industrial economic development. The resulting indicator is used to develop targets for the spatial development of Russian regions, as well as to assess the effectiveness of spatial strategizing tools.

The provisions of the Spatial Development Strategy of the Russian Federation for the Period up to 2025, approved by the order of the Government of the Russian Federation on December 27, 2019 No. 3227-r [13], require further improvement due to changes in environmental factors and the need to clarify conceptual approaches to the patterns of spatial organization economy. Therefore, for example, the interpretation of space used by the developers significantly narrows the object and toolkit of strategizing, which does not allow the implementation of the targets of regional policy in the context of growing interregional inequality.

Changes in the information space of the Russian Federation, which aggravated its heterogeneity, were not properly reflected in the provisions of the Strategy. The classification features of regions in the context of the study include:

- digital demand and supply in certain sectors of economic activity;

- the state of information and knowledge resources, and the efficiency of their use, their share in the growth of GRP;

- the level of misbalance in access to information and communication networks (the digital gap of the "first level"), the volume of information and communication competencies and the effectiveness of ICT use (digital gap of the "second level"), the level of social inequality caused by digital transformation (digital gap of the "third level") [14-15].

It seems necessary to supplement the tools for implementing the spatial development strategy with a number of activities. Among them is the development of institutions of competition for manufacturers of information platforms and end-to-end digital technologies 
in order to identify domestic manufacturers and local markets of high-tech equipment for participation in international cooperation [16-17]. The specified formulation of the problem proceeds from the recognition of the heterogeneity of space and the role of "poles" of growth in its development, as well as from the refusal to identify subspaces on the basis of an administrative and territorial basis in favour of taking into account the attributive characteristics of space (density, frequency, intensity and volume of interactions). Environmental characteristics of space [18-19] also must be considered.

The stages of development of the information society, where the completeness and speed of solving the priority tasks of the third industrial revolution (Industry 3.0) were determined by the effectiveness of the administration mechanism and the volume of investment costs in the development of innovative infrastructure facilities. Unlike this, the stage of information and communication space development presupposes the creation of conditions for stimulating digital supply and demand. In this regard, it seems necessary to transform traditional activities (for example, the use of crowdfunding in the field of investment activities, etc.) to innovative activities (turnover of cryptocurrencies, etc.). At the same time, the polarization of the information space is understood as a key factor determining interregional misbalances in the context of a systemic digital transformation of the economy. It provides the need for the accumulation and development of information and knowledge resources, a qualitative change in the content of inter- and intraregional, inter- and intra-sectoral interactions with the system of social reproduction and state management under the influence of digital technologies to preserve the quality of environment.

\section{Conclusion}

The study showed that in the period from the 1990s to 2010 a certain model of strategic planning was dominated, in which the role of the "center" was played by the locomotion regions, and the role of the "periphery" - by the depressed regions (typology of the regions of the Ministry of Regional Development of the Russian Federation, which was abolished in 2014). It served as the starting point for the formation of the strategy inter-regional alignment. Instead of the specified two-level model used by the developers of the Strategy, we propose a methodological approach based on the recognition of the multipolarity of the economic, information, and environmental space. The spatial approach involves taking into account the entire set of economic, technical and technological, institutional, cultural, social and other factors, in their co-evolution. National (regional) positioning is a prerequisite for adapting spatial strategizing tools to its object. This contributes to the adaptation of the strategy of balanced spatial development to the peculiarities of regional formations.

The spatial approach to the economic development of regions makes it possible to adapt the provisions of the program documents of the Russian state (spatial development strategy) to the current state of the information space of the constituent entities of the Russian Federation. This ensures the balanced development of the economic, informational and environmental development Russian regions. It implies coordinated institutional design, strategic and budget planning, stimulating budgetary and financial policy, taking into account environmental problems, the influence of space structuring processes on the dynamics of the main mesoeconomic indicators.

\section{References}

1. M. Yazevich, O. Kalinina, O.Zhironkina, E3S Web of Conferences 134, 03004 (2019) 
2. A.N. Tokarev, Economics and Innovation Management 1, 25-35 (2018) DOI: 10.26730/2587-5574-2018-1-25-35

3. A.N. Tokarev, Economics and Innovation Management 3, 46-51 (2017) DOI: 10.26730/2587-5574-2017-3-46-51. DOI: 10.26730/2587-5574-2017-2-11-23

4. S.A. Zhironkin, K.A. Kolotov, O.V. Zhironkina, Economics and Innovation Management 1, 4-16 (2017) DOI: 10.26730/2587-5574-2017-1 -4-16

5. A.A. Radugin, U.F. Boymatov, Bulletin of the Voronezh State University. Series: Philosophy 3, 194 (2017)

6. I.F. Devyatko, Modernization, globalization and institutional isomorphism: towards the sociological theory of global society (Institute of Sociology RA, Moscow, 2001)

7. O.E. Williamson, Markets and Hierarchies: Analysis and Antitrust Implications (The Free Press, New York, 1975)

8. N.L. Udaltsova, Creative Economy 13(1), 49-62 (2019)

9. A.V. Myaskov, S.M. Popov, Economics and Innovation Management 1, 16-24 (2018) DOI: $10.26730 / 2587-5574-2018-1-16-24$

10. M. Cehlár, J. Janočko, Z. Šimková, T. Pavlik, E3S Web of Conferences 15, 01019 (2017)

11. L.V. Lapidus, L.S. Leontyeva, A.O. Gostilovich, Public Administration. Electronic bulletin 77, 212-228 (2019)

12. Measuring the knowledge economy: theory and practice (PRAN RAN, Moscow, 2008)

13. RF Government, The strategy of spatial development of the Russian Federation for the period up to 2025 (approved by the order of the Government of the Russian Federation dated February 13, 2019 No. 207-r). URL: http://government.ru/docs/35733/

14. Digital life of Russian regions: what determines the digital gap (Institute for Emerging Markets Research at Skolkovo Business School, Moscow, 2020)

15. E. Dotsenko, N. Ezdina, D. Cagáňová, S. Mudrova, E3S Web Conf., 174, 04039 (2020)

16. E. Dotsenko, N. Ezdina, D. Cagáňová, S. Mudrova, E3S Web Conf. 174, 04039 (2020)

17. E. Dotsenko, D. Galoyan, E. Burdenko, S. Mudrova, E3S Web Conf. 174, 04041 (2020)

18. E. Dotsenko, N. Ezdina, S. Mudrova, E3S Web Conf. 41, 04050 (2018)

19. E. Dotsenko, N. Ezdina, S. Mudrova, E3S Web Conf. 105, 04039 (2019) 